\title{
Ssciendo
}

Ethics \& Bioethics (in Central Europe), 2021, 11 (3-4), 163-180

DOI:10.2478/ebce-2021-0015

\section{Equitable global COVID-19 vaccine allocation and distribution: Obstacles, contrasting moral perspectives, ethical framework and current standpoints}

\author{
Georgios Kalaitzidis ${ }^{1}$
}

\begin{abstract}
Accelerated COVID-19 vaccine development represents an important accomplishment and a milestone in the history of vaccine evolution. However, the vaccine's scarcity made its equitable global allocation and distribution ambiguous. Despite the initial pledges from wealthy countries for fairness and inclusivity towards the poorer ones, the policies followed diverged significantly. Wealthy countries have vastly superior access to vaccines in a reality likened to an ethical disaster. This paper calls for the need for fair global vaccine allocation and distribution and examines the barriers that were met along the way, originating from different points, such as the nationalistic approach on the matter that most wealthy countries have adopted or the inability of poor countries to purchase or manufacture vaccines. Further, a suggestion regarding the ethical principles and values that ought to guide global vaccine allocation and distribution is provided with a higher priority given to helping the worst-off, saving the most lives, protecting people in high risk, such as frontline healthcare professionals, and minimising social gaps, along with an ethical theoretical background for each prioritisation. It is not too late for wealthy countries to realise that vaccine inequity prolongs pandemics, so that they change their policies in favour of the global common good that will not only provide immediate universal benefits but will also serve as a guide for future pandemic crises.
\end{abstract}

Keywords: COVID-19, vaccines, access, global, equity

\section{Introduction}

With coronavirus (COVID-19) affecting an increasing amount of the global population, vaccines have emerged as a powerful weapon in the arsenal of public health policies. The lives of millions of people are in danger with more than a million deaths from the virus worldwide, and national economies suffering deep downturns. This situation serves as the latest demonstration of how detrimental infectious diseases can be in the absence of an effective vaccine (IMF, 2020). In 1918, an influenza outbreak (Spanish Flu) killed more than 50 million people globally and had devastating socioeconomic impacts (Martini et al., 2019). In another case of different geographical and socio-economic backgrounds, over the course of 2 years (2014-2016) the Ebola virus was responsible for the death of approximately 11,000 people in West Africa due to rapid viral spread across several countries (Brown, Mepham \& Shorten, 2017).

Most nations are attempting to secure adequate access to an effective and safe vaccine, which combined with other public health measures, including masks, social distancing and extensive testing may help to limit the spread of the disease (McNeil Jr., 2020). Therefore, there is a general belief that a COVID-19 vaccine could put an end to the current pandemic, re-enable free movement, drastically decrease the number of deaths, help economies recover, and improve the physical and mental welfare of people. However, this is only partly accurate. Even in the presence of a potential vaccine, COVID-19 will stop posing a threat only if enough people (more than $60-70 \%$ of the global population) are consenting and given the opportunity to get vaccinated (Aschwanden, 2021). This matter raises several compelling ethical issues regarding vaccination strategies and policies. Vaccination decisions and programs to a certain extent impact both vaccinated and non-vaccinated individuals as well as the wider community and therefore should be considered as ethical decisions.

Currently, due to efforts from the global scientific community, unparalleled in speed, resource allocation and scientific focus, there are at least 308 vaccine candidates, of which 16

\footnotetext{
${ }^{1}$ Charles University Prague (Czech Republic); georgekalaitz@hotmail.com; ORCID: 0000-0002-4693-9270
} 
have reached late-stage development. ${ }^{2}$ At the time of drafting this report, the Moderna and Janssen vaccines have been approved for emergency use against COVID-19 virus by the European Medicines Agency (EMA) and the Food and Drug Administration (FDA). Notably, the Pfizer-BioNTec vaccine received full approval by the FDA and emergency use approval by the EMA. Additionally, there is a contingent marketing authorisation for the OxfordAstraZeneca vaccine provided by the EMA (Chakraborty et al., 2021; Waxman et al., 2021; Forni \& Mantovani, 2021; Peiffer-Smadja et al., 2021; FDA, 2021). They can potentially prevent thousands of deaths and shield vulnerable individuals, but it seems ambiguous whether the obstacles associated with their vast production and equitable distribution can be overcome.

The cooperation between the World Health Organization (WHO), humanitarian and private sector companies, combined with their Access to COVID-19 Tools Accelerator, led to the declaration of $24^{\text {th }}$ April 2020, supposedly ensuring just, global access to "safe, quality, effective, and affordable COVID-19 diagnostics, therapeutics and vaccines" (WHO, 2020). Most countries have already started materialising their pledges (Miller, Shields \& Farge, 2021). ${ }^{3}$ (Miller, Shields \& Farge, 2021). Moreover, in 2000 the Global Alliance for Vaccines and Immunisation (GAVI) was created which has secured billions in donations from public and private organisations to aid vaccination in low-income countries where vaccination normally faces various barriers, such as inability to afford vaccines and supplies, insufficient healthcare structures and resources to vaccinate (Zerhouni, 2019). Importantly, a multiparty alliance between GAVI, the Coalition for Epidemic Preparedness Innovations (CEPI), and the WHO created COVAX to set up the framework for equitable access to vaccines globally, with the promise to cover the vaccination need of 92 middle and low income countries (MLICs) and immunise 20\% of their population within 2021 (Loembe \& Enkegasong, 2021). Nevertheless, the global scarcity of vaccines, high costs, and exacerbating injustice and disparity observed during pandemics likely aggravate the vaccination barriers that low-income countries continually face (Torres et al., 2021; Bong et al., 2020). Therefore, it remains extremely unlikely that donations and interventions from developed countries will ensure fair distribution of vaccines against COVID-19 without the existence of a concrete, well-defined ethical framework for allocation adopted by everyone.

The real challenge is identifying the most efficient and ethical approach that would achieve equitable global vaccine allocation and distribution. One approach examines the issue through a more consequentialist or utilitarian scope, advocating that the outcomes or consequences of an action or adopted policy determine its moral justification. In practice, when a particular result is defined as good then the action that allows its maximisation is the ethical one. A second approach, based on a more deontological perspective, proposes allocating COVID-19 vaccines according to good principles or standards. According to this perspective, equity and fairness are the two fundamental values that should govern vaccine allocation, even if it means that sometimes it compromises efficiency. This way, vaccination can lead to decreased suffering, reimbursement of the people who were exposed to high risk during the pandemic and even enhance post-pandemic equity. However, such an approach has to deal more with complex and compelling ethical questions, such as identification of the most vulnerable or evaluating who was affected the most. An ideal approach would be an amalgamation of both these perspectives. In my view, embedding the consequentialist reasoning (e.g., maximising benefit, limiting harm) within a deontological framework (e.g., prioritising the socially disadvantaged, equal concern) would fit current COVID-19 vaccine allocation needs.

\footnotetext{
${ }^{2}$ All these vaccines differ in physiological response to varied dose, effectiveness and supply network demands.

${ }^{3}$ Including United States which initially refused to support it.
} 


\section{Vaccine as a Global Public Good}

For the purpose of this paper, I will refer to all COVID-19 vaccines as "the vaccine". As the COVID-19 vaccine was initially approved for emergency use there were several voices advocating for its declaration as a Global Public Good (GPG), that would influence its fair global allocation and distribution (UNESCO, 2021; UN, 2021; Yunus, Donaldson \& Perron, 2020). Therefore, it would be beneficial to briefly define this concept. Originating from classical liberal economics, the concept of Global Public Goods has been utilised to subsidise equitable global distribution of social aid, such as health services. Public goods are goods that fulfil the two requirements of being non-excludable and non-rivalrous in nature. A good is nonrivalrous when its utilisation by one does not stop others from utilising it and non-excludable when every individual benefits from it despite how many other individuals do (Samuelson, 1954). Innately, they raise specific ethical questions regarding fairness and free-riding. The contribution from an individual is not compulsory in order to benefit themselves, or others, from it; therefore, the problem of free-riders occurs. The existence of free-riding is unethical, and sometimes even illegal, because it compromises fairness (Giubilini, 2021).

Multiparty negotiations were held to decide whether the vaccine should be declared as 'global public good'. ${ }^{4}$ However, it was finally decided to declare 'herd immunity' acquired by the vaccine as GPG instead (WHA, 2020). 'Herd immunity' is the situation when the majority of a population is immune to an infectious disease, providing indirect protection to those not immunised against the disease. For instance, immunising $80 \%$ of a population against a virus means that four out five people who come across someone with the disease will not become ill or transmit the disease. The herd immunity threshold of any disease depends on how infectious the pathogen is and the efficacy of the potential vaccine (Fine, Eames \& Heymann, 2011). From an ethical perspective, herd immunity is a public good and raises the already mentioned ethical questions regarding fairness and free-riding since not all people need to get vaccinated in order to achieve it (Lim, Zhang, 2020). According to certain sources, an individual's denial to contribute to herd immunity because it is immaterial, is a contravention against fairness (Giubilini, 2019).

An emerging question is whether herd immunity specifically for COVID-19 is still an achievable goal. The answer is positive, but does not mean the immunity level in society will soon be at such a degree as with other infectious diseases, such as measles or mumps, that would allow us to say that the crisis has disappeared. The world will have to get used to the idea of coexisting with the virus for several years due to various reasons. One reason is the difficulty to get people vaccinated against COVID-19 globally. Unlike measles vaccination, many people have been significantly sceptical towards the COVID-19 vaccines, even if we already know that they are safe and provide protection against the virus, including the dominant B.1.617.2 (delta) variant. Secondly, children are still not widely qualified for vaccination and until that happens there will be a continuous COVID-19 circulation among children, who will subsequently infect mainly unvaccinated adults. Thirdly, the uneven COVID-19 vaccine rollout is significantly hampering the global goal of herd immunity for COVID-19. "No one is safe until everyone is safe" became the global slogan for COVID-19 pandemic for a good reason. Fourth, even though COVID-19 vaccines are extremely efficacious and decrease the risk of infection, this risk is not completely eradicated. Vaccinated people or people with natural immunity against COVID-19 can still become infected. As a result, an increased vaccination rate is required in order to achieve the desirable herd immunity. Since complete elimination of COVID-19 virus is unlikely, it might continue circulating in the population until a large portion of the population is exposed to it. Further, vaccinated people have significantly less probability of infection and in case they do become infected, they experience a milder version of COVID-

\footnotetext{
${ }^{4}$ Approximately 100 participating member countries suggested it to be part of a World Health Assembly resolution in response to COVID-19.
} 
19 and are protected against its most severe complications. Hence, the goal of herd immunity for COVID-19 is different than herd immunity for other infectious diseases. In the case of COVID-19, the desirable goal is to achieve an immunity level within the community that will render the COVID-19 outcomes controllable (D'Souza \& Dowdy, 2021; Klass \& Ratner, 2021; Yigit, Ozkaya-Parlakay \& Senel, 2021; Dong, He \& Deng, 2021).

\section{The need of global vaccine allocation, obstacles and different moral approaches}

Despite initial pledges from developed countries regarding equitable global access to vaccination against COVID-19, the reality resembles an ethical catastrophe. At the time of writing, approximately 3.73 billion people have received at least one dose of the vaccine globally, with 1.03 billion people being fully vaccinated. However, it is highly concerning that only $1.1 \%$ of people in low-income countries have received at least one dose (Mathieu et al., 2021). The significant discrepancy regarding COVID-19 vaccination among different income groups is expressed even more by the fact that an important level of protection is out of reach for low-income countries until at least 2023 and that vaccination rates must increase nineteen times in order to reach $40 \%$ immunisation of their populations (Padma, 2021). This discrepancy brings into light the first primary element governing global distribution which is a county's purchasing power. The majority of the world's vaccines are produced by five international companies who negotiate with governments and private organisations for buying (McLean et al., 2016). Furthermore, during the COVID-19 pandemic, a very small number of countries possess the technological means and capacity to produce vaccines against the virus which represents the ability to develop. This is the second primary element determining global distribution. Vast technology transfer between countries is essential to accelerate global vaccine production capacity (Gates \& Gates, 2020; WHO, 2021). Nonetheless, low-income countries contribute in drug development and testing in different ways, e.g., providing virological samples or participants for clinical trials (Alemayehu, Mitchell \& Nikles 2018; Fidler, 2008). This behaviour should be rewarded fairly with priority post-trial access to medications in order to improve equitable distribution through a reciprocal system.

Consequently, insufficient global efforts to fairly distribute vaccines, are already establishing citizenship as the most important factor deciding vaccine distribution. In a nationalistic approach that favours unethical and inequitable allocation, these nationalistic interests of wealthy nations, such as the United States of America, have been expressed in various ways, e.g. the United States' initial refusal to join COVAX claiming potential selfsufficiency or by high-income countries purchasing $85 \%$ of the COVID-19 vaccine doses distributed up to date and vaccinating 12-year old children with low-risk of a severe infection instead of donating to the vulnerable populations of low-income countries (Rauhala \& Abutaleb, 2020; Cohen \& Kupferschmidt, 2021; Yamey, 2021).

During a pandemic, governments have a wide array of duties, such as cross-border responsibilities, since viruses do not recognise countries or borders (Lee et al., 2020). Therefore, the argument for equitable global allocation could be supported even on a strict nationalistic frame. Failure of a country to contain a virus within its borders exposes populations everywhere to a threat. Moreover, considering that many inhabitants of middle or low-income countries will most likely remain unvaccinated until 2023 and therefore uneven global vaccine distribution will continue, the potential consequences will be devastating (Ekstrom et al., 2021). The COVID-19 virus might mutate into variants which could render some of the vaccines ineffective, prolonging the pandemic and thus allowing more potential severe infections and deaths (WHO, 2021). Hence, a perspicacious government would allow distribution of the vaccine outside their borders, after vaccinating the required part of its population.

Contrasting ethical perspectives buttress discussions regarding national versus global vaccine distribution. The main idea behind vaccine nationalists is moral nationalism, the ethical 
perspective that an individual has a special concern and duty for people with whom they share the same nationality and citizenship (Tan, 2004). On the contrary, moral cosmopolitanism is the rival of moral nationalism and the main idea behind those who support global vaccine allocation and distribution. Throughout history, moral cosmopolitanism has been given several different interpretations. For example, for the Stoics, human beings are not seen as members of provincial political societies but as citizens of the world. According to Kant, the community of moral argument is where all human beings belong and are a part of, an understanding that expresses the universality of the position of moral argument. More recently, the term has been adopted to describe a broad range of cultural, political or legal perspectives. Nonetheless, the most prominent contemporary perception is connected to none of these perspectives and it better relates to our comprehension of the virtuous state of human individuals. According to the latter, there are three common elements in all cosmopolitan interpretations. First is individualism, meaning that human beings or individuals are the ultimate unit of moral concern rather than states, nations, family bonds, religious, political, legal, or cultural associations, which can be units of moral concern merely indirectly as a result of their individual human beings. The second element is universality, advocating that each living human individual, irrespective to the subgroup where they might belong, such as men or nobles, is equally entitled to the status of the ultimate unit of moral concern. Thirdly, generality renders the power of this exceptional status universal, meaning that every human being is the ultimate unit of moral concern not solely for their fellow compatriots or people with whom they share a common religious, political or suchlike idea, but without exception to everyone (Held \& Maffettone, 2017; Pogge, 1992). Interestingly, we can observe that both perspectives share a common characteristic. They both recognise that the need for duties to 'compatriot' or 'foreign' individuals might arise for distinct reasons, such as the need for efficiency or the goal of the optimal benefit (Tan, 2004; Pavel, 2009). In addition to moral cosmopolitanism, cultural cosmopolitanism depicts a particular perspective and represents another idea that favours global vaccine allocation and distribution. For cultural cosmopolitanism, an individual's welfare is irrespective of their belonging to a specific culture and therefore supports cultural diversity, blending and the fluidity of an individual's distinctive identity (Scheffler, 2002). However, a moral nationalist might claim that all forms of cosmopolitanism are a tool for poor countries to receive aid from the wealthy ones.

There is a growing belief that wealthy countries have a moral obligation and ought to do much more to help low-income countries, particularly to ensure their access to the advantages of modern medicine and state-of-the-art technology. Many experts have indicated the responsibility of wealthy nations to provide greater assistance to developing countries to counteract the HIV/AIDS epidemic in Africa (Nelson, 2002). This belief is the intersection point of various justice concepts debating distributive principles often applied to healthcare prioritisation. For instance, according to sufficientarian justice, the question whether a society is fair depends on whether each individual has the opportunity to secure enough goods to lead a minimally satisfactory life (Shields, 2020). Luck egalitarianism separates inequalities in two categories: fair inequalities, resulting from individuals' intentional and fully knowledgable decisions (option luck) and unfair inequalities, resulting from decisions over which individuals have no control (brute luck). Inequalities ensuing from brute luck ought to be corrected since a person should not have less currency of goods or any metric than anyone else due to brute luck (Dworkin, 1981). Next, prioritarianism advocates the idea that it is more important to improve the well-being of people and especially of those who are the worst-off. It is distinct from egalitarianism in the sense that it finds higher intrinsic morality in benefiting worse-off people than better-off people and that the concern for benefiting the worse-off is irrespective of the benefit's outcome (e.g., if the comparative welfare level difference between them and the better-off individuals elevates) (Nielsen, 2021). Lastly, utilitarian justice places more weight 
on the equal promotion of everyone's well-being. All these justice principles align with moral cosmopolitanism and diverge from moral nationalism. Importantly, all of them place extra weight on the importance of human life and consider the duty to improve the life of the lessfortunate, regardless of their place of origin, fundamental in a humanitarian approach, that I believe if adopted, would define vaccines as essential goods for the preservation of health and life globally.

\section{The ethics that should guide global vaccine allocation and distribution}

This failure of the developed world to establish and follow a well-defined and structured ethical framework for a global up to date COVID-19 vaccine allocation and distribution, has resulted in vaccine inequity that aside from prolonging the COVID-19 pandemic, has various consequential implications, such as hampering nations' financial recovery and the further spreading of the virus (WHO, 2021; Padma, 2021). Assuming that there is still time for governments to change the allocation and distribution pathway that they follow, setting the ethical principles that should govern this pathway is essential in order to make easier the decision-making and determining which policies should be adopted.

\section{Prioritising people with the most urgent need}

The populations of poor and developing countries, which can be seen as the worst-off, need to be among the first priorities in global COVID-19 vaccine allocation and distribution. Prioritarianism, that has already been slightly referred to above, is a generally plausible and broadly shared distributive value that fits properly the needs of the COVID-19 vaccine priority setting. According to prioritarians, benefiting the worst-off has a bigger intrinsic moral weight than benefiting the better-off people, that distinguishes prioritarian weighting from utilitarianism or egalitarianism, which would prioritise the worst-off following a different rationale based on reducing marginal utility or improving inequalities. Practically, this means that we ought to benefit the worst-off individuals, irrespective of the utility-related or inequality reducing outcomes that this action will yield. Further, a second distinct principle of prioritarinism, advocates that benefiting the worst-off is based on their absolute (not comparative) level of wellness, and could be favoured irrelevant of the fact that the comparative difference between them and the better-off might increase as a result (Parfit, 1997).

One interpretation of the general prioritarian concept is the social justice prioritarianism. This theory suggests that the priority principle should condition the distribution of resources, such as the COVID-19 vaccine, and opportunities in the society, with the principle of benefiting the worst-off, having a higher moral intrinsic value. A justice principle that takes into special consideration the worst-off individuals is the right one to adopt since every rational and logical human-being recognises that the inequalities of these unfortunate groups are uneven. On the other hand, if we were deciding the values that ought to govern the vaccine allocation unaware of our own situation, a principle that would prioritise the worst-off should again be preferred. Therefore, I conclude that social justice prioritarianism can be defended on both consequentialist and contractualist grounds (Adler, 2012; Holtug, 2010; Rawls, 1971; Scanlon, 1998).

Social health factors shape health deficiency and vulnerability. However, this occurrence spotlights not only the wide social gap between the rich and the poor, but the existence of a constant universal health social gradient within society. Socially disadvantaged populations are more susceptible to health hazards, have a shorter lifespan and a lower quality of life compared to socially privileged populations. This is a result of different determinants, such as high population density, lack of clean water or food, poor housing conditions that increase the possibility of infection, low socioeconomic status, insufficient sanitation, limited access to healthcare, and significantly higher risk of poor outcomes. Further, limited, or even absent, 
healthcare access establishes vaccinations as the most important preventive intervention, (Sadmi et al., 2020). All these factors highlight the socially unequal distribution of health risks and the urgent necessity to receive the vaccine. Consequently, these populations have the most urgent healthcare needs (Acheson, 1978). ${ }^{5}$ Nonetheless, health needs should not be confused with healthcare needs (Wright, 1998). ${ }^{6}$ Pandemic distributional outcomes place additional and disproportional weight mainly on the socially unprivileged and we have strong prioritarian reasons to protect the worst-off against the COVID-19 pandemic and ask healthcare systems to alleviate these unfair harms by giving them priority access to the COVID-19 vaccine.

At the top of prioritised groups in every country should be older adults who belong to the worst-off population groups. This is mainly due to their urgent healthcare needs, their high susceptibility to a severe COVID-19 infection and subsequent death, and their high benefit from preventative measures against the disease, such as face masks and social distancing. It is a moral duty to protect the elderly and, by giving them the vaccine, the possibility of infection is significantly decreased, and thus the social duty is carried out (Mallapaty, 2020; WHO, 2020). A high mortality rate due to COVID-19 is connected to advanced age worldwide. For instance, in the early stages of the epidemic in Italy, advanced age was associated with increased mortality, particularly around $80 \%$ of deaths occurred in patients over 70 years old, while in South Korea the mortality rate was higher in patients over 60 years old (Kang \& Jung, 2020; Amore et al., 2021). It is important to mention though that prioritising the elderly opposes the view of age-weight prioritanism according to which the younger an individual is, the more important it is to save them. (Tsuchiya, 2000; Bognar, 2008). ${ }^{7}$ Nonetheless, I believe that this perspective is not congruent with needs of COVID-19 vaccine allocation because it does not take into consideration the important duty of prioritising socially underprivileged populations and focuses strictly on the augmentation of life years based on age.

Another interpretation of the prioritarian idea is severity prioritarianism that views treating the most severely sick as fundamental. However, it can be argued that severity can be viewed as a multivariate idea, calling on urgency, fairness, and saving lives amongst others. Hence, protecting the individuals most prone to severe illness ought to be considered a profound duty as well. In practice, one possible explanation of severity prioritarianism can be provided by setting health deficiency as the base for the strict definition of the worst-off. Consequently, the most severely sick individuals or those with a higher risk of developing the most severe disease are considered as the relevant worst-off. The application of a prioritarian scope, suffering severely from COVID-19, that always includes the possibility of death, most likely establishes suffering people as worst-off compared to other individuals over the course of a life. According to this rationale, groups that should be given high priority include individuals with immunodeficiencies and patients with various underlying diseases, especially ones associated with a higher mortality rate due to COVID-19, such as hypertension, diabetes and obesity. All these groups are significantly susceptible to severe illness and society should not just recognise and list the predicaments of each group, but acknowledge the way that each predicament contributes to poor outcomes.

\footnotetext{
${ }^{5}$ A healthcare need is defined as a need that requires medical care services and represents a humanitarian perspective since it implies that when human suffering occurs, clinical intervention is required to alleviate it.

${ }^{6}$ In the case of a health need, the potential benefit does not come strictly from a medical service but also from a wider set of factors, such as environmental or social variables.

${ }^{7}$ This theory advocates that an untreated disorder at an early stage of human life will make life harder than an untreated disorder at a later stage in the course of a lifetime and indicates the injustice of a younger person being deprived of the opportunities that an older person has already enjoyed in life.
} 


\section{Saving as many lives as possible}

The value of saving the most lives represents another principle that ought to govern global vaccine allocation and distribution, meaning that the most worthy action is saving lives and can be understood as a way of benefit maximisation. However, it can be defended from both a utilitarian moral perspective that focuses more on population consequences and a non-utilitarian scope that highlights the supreme worth of each human life (Kerstein, 2017). Practically, this value could be implemented to determine how many lives would be saved if equitable global COVID-19 vaccine allocation was promoted or not. For this purpose, the following variables should be examined:

1) Probability: Let us hypothesise that the implementation of equitable global vaccine allocation would result in saving 2,000,000 lives and inequitable allocation 500,000 lives. In this case, promoting equitable global vaccine allocation would be the right option since 1,500,000 more people would be saved and hence the benefit will be maximised with justice served equitably (Savulescu \& Wilkinson, 2020).

2) Nature of the resource: While allocating and distributing scarce resources, the fact that resources equal to number of lives should be considered seriously. In particular, for COVID19 vaccine allocation, this fact is even more important since the vaccine will not only increase the receiver's possibilities of a severe infection and subsequent health complications, such as death, but will also decrease significantly transmission to others. Therefore, the benefits to society are maximised both directly and indirectly, in the short-term and long-term.

Maximising lives saved is the main principle behind standard hospital triage implementation during a disaster, such as during the early stages of the COVID-19 pandemic in Europe, aiming to save the most lives by giving priority to patients sick enough to benefit from the potential resource and unlikely to survive without it (Maves et al., 2020). Operationalising the fundamental value of maximising benefits, in allocation and distribution of scarce resources, such as ventilators, during a pandemic relies on the prioritisation of sick patients with a higher chance of not just surviving (higher possibility of being discharged) but surviving for longer with the resource over sick patients with low possibility to survive even with the resource or with a high probability to recover without it. This is contrary to the current allocation needs where the vaccine, as a scarce resource, is most likely to save more lives when distributed to people with a high risk of serious complications or death in case of infection and to old individuals (Persad, Wertheimer \& Emanuel, 2009; Zucker et al., 2015). The current COVID19 vaccine allocation needs are served from a utilitarian perspective since in order to maximise the vaccine's utility and, thus, the benefits, it must reach those people who rely on it the most.

Throughout history, resource allocation during a public health emergency has been shaped by the utilitarian goal of maximising net benefit which can be translated as saving the most lives. Further, it is the most common bioethical approach when trying to address resource allocation during a public health crisis (Bayer et al., 2011). In 2021, Goldstein et al., concluded that vaccinating the elderly with a higher priority not only saves the most lives but also the most years of life (Goldstein, Cassidy \& Wachter, 2021). In support of this finding, Emanuel et al. recommended that, since COVID-19 has more devastating results on older individuals or people with chronic conditions, they should be prioritised over young patients, in a strategy attempting to save the most lives. On the other hand, it was suggested that younger patients should only receive priority if there is scientific proof that it would benefit public health through reduced viral spread and risk of infection (Emanuel at al., 2020).

\section{Quality of life}

For utilitarianism, it is highly significant that the maximisation of lives saved is accompanied by a good level of well-being through the course of each life. Therefore, the quality of life is considered fundamental. However, there is a lot of controversy regarding how to define quality 
of life and what it really means, in an attempt to at least set a minimum quality of life threshold. In general, quality of life is either described directly in terms of the wellbeing acquired from goods or indirectly in relation to the wellbeing acquired from the goods' characteristics. In a non-utilitarian approach, quality of life might be linked to the intrinsic characteristics of people, such as genetic predisposition of health, their relative deprivation irrespective of total commodity consumption or the features of those commodities, their moral value and meritoriousness. Furthermore, it might relate to the nature of relationships among people, such as quality of friendship, community provision for the worst-off and social seclusion, or alterations to their statuses, such as becoming a widow/er or getting divorced. Nonetheless, the most conventional approach is the welfarist one. According to this, not just the quality of life, but also the standard of living, effective social dispositions and distributive justice, are all measured in relation to the utilities of the people involved. The utilitarian ethical value, that the total or average utility must be maximized, characterises this form of welfarism (Culyer, 2012).

In order for an individual to be able to have access, achieve and enjoy an adequate level of life quality, a fundamental requirement ought to be fulfilled. Arora et al. stated that 'unconsciousness or severe disorders of consciousness, such as minimally conscious state' as a permanent result of intensive care would pass below the minimum life quality threshold (Arora et al., 2016). However, in COVID-19 vaccine allocation and distribution, the cause of an unconscious state should be irrelevant, for example, it might be the result of intensive care due to severe COVID-19 complications or due to a car accident or a progressive mental illness. To explain it thoroughly, I will formulate an extreme example. Unconsciousness is the final result of dementia. Imagine that we have two patients, both over 70 years old and candidates to get the COVID-19 vaccine. The first patient has a functioning level of consciousness and the second patient has end-point level of dementia. In the case that we could not administer both with the vaccine, utilitarianism would prioritise the first patient over the second. The second patient would receive no benefit from being protected and kept alive in an unconscious condition. Concerning minor levels of cognitive impairment or disabilities, from a utilitarian scope, if they affect the well-being of an individual they should also be assessed when deciding allocation policies.

Nonetheless, comparing the overall wellness of different individuals can be a deceitful and complex task. It cannot be taken for granted that someone with a disability would have a lower level of wellness and would benefit less from a scarce resource, such as the COVID-19 vaccine, than someone with no disability. For example, someone with a $50 \%$ loss of vision in the right eye will not necessarily have a worse level of wellbeing than someone with normal vision. One of the most intense ethical questions is which factors define a person's life as good or which are the elements of wellness and has been a philosophical topic of debate for centuries. Potential answers to this question include a person's overall happiness, satisfaction of desires, being autonomous and independent, and having strong and meaningful interpersonal relationships (Parfit, 1984; Griffin, 1988).

\section{The multiplier effect}

During the COVID-19 pandemic, the implementation of further selection criteria to guide vaccine allocation and distribution is crucial. According to utilitarianism, all actions have consequences, direct and indirect, short-term, and long-term, and they are all associated with decisions. Therefore, it would be useful to contemplate not only the benefit for a person affected by an action but also the benefit that this action might have for others. ${ }^{8}$ I propose that on a global scale, frontline healthcare professionals with increased exposure to the virus due to their workplace should be highly prioritised for vaccination in an attempt to maximise the utility.

\footnotetext{
${ }^{8}$ Social worth or social benefit.
} 
This category includes not only physicians, nurses and clinical pharmacists but also respiratory technicians or any other category of worker providing important benefits to others. Prioritising frontline healthcare professionals can be ethically justified using three main arguments. Firstly, by giving them priority, a society benefits not only themselves but also all the people that they take care of in hospitals or clinics during the pandemic, creating the multiplier effect that increases benefits. The multiplier effect, also known as "narrow social utility" is a value advocating that certain occupations should be prioritised due to their short-term value to the community during a public health emergency or crisis. This short-term value is measured in terms of saving lives, keeping the critical infrastructure operating or prevent societal disintegration through the practice of certain professions. ${ }^{9}$ Therefore, front-line healthcare professionals and individuals who care for ill patients ought to be treated with the highest priority since they are essential for the smooth and efficient operation of the critical healthcare system and/or their protection is beneficial for the society's common good (Childress, 2003; Emanuelson et al., 2020; Winsor et al., 2014).

A narrow social utility example occurred in World War II when penicillin was considered a scarce resource and was firstly administered to soldiers who were suffering from syphilis but were able to make a full recovery and go back to fight rather than to soldiers with severe injuries unable to return to battle (Beecher \& Dorr, 1970). During a pandemic, there might exist a sufficient number of ventilators but a shortage of expert personnel able to handle them. Therefore, vaccinating the healthcare providers may prevent them from getting sick or recover fast enough so that they can continue saving lives. This assumption, however, relies both on the duration of the COVID-19 pandemic and the speed of the recovery so that the individual can return to work.

The second argument for prioritization of frontline healthcare professionals relies on the nature of their profession that includes the possibility of harm during the practice of their profession and the subsequent service to society (infected while caring for others). A way to better analyse it is by using the social contract metaphor which advocates that the agreement of healthcare professionals to put themselves at risk while serving society by treating the ill, is rewarded by society with advantages and powers. As part of this agreement, the society ought to protect healthcare professionals from getting sick or care for them in case they do (Cruess \& Cruess, 2010). A third and final argument, calls on society's moral duty to benefit those who benefit society, which constitutes the value of reciprocity which assigns duties not only on the side of healthcare workers but also on the side of governments and other private individuals (Becker, 1990)

An important arising question is what happens about the social worth of others. Should other population groups such as immigrants, prisoners, lab scientists, pregnant women, dependent children, parents, and athletes have lower or higher priority access to scarce resources, such as the COVID-19 vaccine? The complexity of developing rules for assessing social worth is very high from both an ethical and epistemic perspective and critical level utilitarianism would most likely not support such prioritisation, except of essential frontline healthcare professionals or people with serious health comorbidities, such as diabetes, since they have a high degree of clarity, is easy to apply and has broad social approval. Notably, operationalised utilitarian values are prone to potential misuse. Hence, when the risk of value misuse is identified, it should be assessed to determine whether to operationalise the value or not. For instance, the argument of advantage is used by the mighty to misuse social worth.

Another important objection is dealing with the appearance of favouritism created by the decision to prioritise frontline healthcare professionals. Giving priority to this group should not be received as a form of favouritism due to their higher societal value but solely because, at this

\footnotetext{
${ }^{9}$ Further, this short-term value is what distinguishes narrow social utility from broad social utility, which judges the collective individual's value to society.
} 
particular instant, they are the most suitable people to keep society operating and prevent its collapse, manifesting their short-term value to society. This selection has been strictly based on maximising utility and thus the benefit and is reflected in my proposal to include, in the frontline healthcare professionals group, not only strictly physicians, nurses and clinical pharmacists but also any other individual providing important services to benefit other people. Nonetheless, I consider the narrow social utility approach a little problematic in the current COVID-19 pandemic, if applied blindly and unanimously worldwide without taking into consideration various other parameters, such as the estimated duration of the crisis at the national level, and geosocioeconomic factors, such as origin, age group, socio-economic background and comorbidities that could affect recovery speed, the susceptibility to infection and the severity of a potential infection. All these parameters could influence the ethical rationale for such prioritisation. To explain it properly, I will present an example. We hypothesise that the duration of a COVID-19 wave crisis in Greece is three to four months. On one hand we have Nikos, who is a 26 year-old pharmacist at a Greek hospital and has no underlying conditions, such as diabetes, obesity or hypertension. He is mainly responsible for inventory control of drugs that plays a pivotal role in hospital management. However, due to the nature of his position, his contact with physicians (most of them have already been vaccinated and thus they have a significantly small transmission rate) within the hospital is small and he rarely enters rooms where infected people have been placed. On the other hand, we have Kostas, a 55 yearold Greek postman, who is a heavy smoker and has diabetes mellitus type 2 and chronic obstructive pulmonary disease (COPD). He comes in daily contact with various people (we cannot know the vaccination rate among them) while delivering their letters and parcels. If we cannot give the vaccine to both of them, prioritising Nikos over Kostas strictly because he is a frontline healthcare professional might not be the ideal solution. Kostas most likely has a higher risk of severe infection, due to many factors, from COVID-19 and serious subsequent health complications, such as the need for intensive care or even death and thus by giving him the vaccine, we maximise the utility and the net benefit. Moreover, even if Nikos gets infected, the condition of his health and his age are likely such that will most likely allow him to recover fast enough and return to work before the end of the crisis even without the help of the vaccine. Therefore, a more personalised evaluation, even if more complex and time consuming, would be a step in the right direction.

\section{The booster controversy}

Several wealthy countries, such as Israel and Germany, have announced plans to begin boostershot administration in August 2021 in an attempt to further safeguard their populations against COVID-19 infections. The third dose administration is based mainly on the fear of the dominant delta variant that emerged from poorer countries, without clear definite evidence that would justify this revaccination need. The WHO recognises the need for an additional vaccination for specific reasons, such as decreased protection from severe infection due to weakening immunity, lower protection against emerging serious variants that render the existing vaccination insufficient and ineffective protection from the currently recommended vaccination regimen for some risk groups. According to the WHO, though the logic underlying booster doses may vary according to vaccine manufacturer, epidemiological setting, risk group and vaccination coverage rate. A booster is an additional mRNA-based vaccine shot on top of the previous ones, that increases the level of antibodies against the pathogen after the drop that occurs approximately 2 to 3 months post complete vaccination. The level of antibodies will decrease once again but the collection of memory B-cells, that protect the organism from future infections by this pathogen, will be significantly larger than before. Nonetheless, this decision of wealthy countries has been highly criticised by activists and non-profit organisations around the world, such as Doctors Without Borders (DWB), on the grounds of worsening the already 
unfair global vaccine allocation and distribution and exacerbating social gaps, and the WHO called for a moratorium to be applied on booster shots at least until the end of September 2021 in favour of unvaccinated people who represent the majority of the world. Further, global-health researchers assert that each booster administered equals a vaccine that could be given to a citizen of a middle or low-income country where the majority of the population is unprotected and subsequently serious COVID-19 variants might emerge (Maxmen, 2021; The Lancet Infectious Diseases, 2021; Callaway, 2021; UCL, 2021; WHO, 2021). Considering the fact that access to healthcare, such as vaccination, is probably the most fundamental social primary good since diseases and health disorders can damage a society's overall happiness and satisfaction, seriously affecting self-confidence and self-esteem, the equitable provision of this good should be made available equitably to all people universally. Depriving poor countries from the vaccine, and instead providing it again to citizens of wealthy countries where more than half of their populations have received the primary series of the vaccine and all consenting essential workers and adults have been immunised, would be highly questionable for utilitarians who would rather prioritise those at a higher risk of infection from the virus and subsequent serious health complications. The utilitarian position takes these vulnerable populations into consideration and by giving them priority relieves not only the increased social stress during this time but also the increased stress at hospitals.

The rationale for booster-shots might be justified in terms of protecting public health and fighting the virus but the timing and ethical background of this decision is problematic. With wealthy countries having been able to administer 100 shots per 100 citizens and poor countries only 1.5 shots per 100 citizens, the booster dose policy will worsen inequities and injustice since it will increase the consumption of scarce resources by wealthy nations while at the same time even priority groups of poor countries have not been able to receive the vaccine's primary series (WHO, 2021). This injustice is highlighted even more by the fact that citizens of LICs have a higher vaccination acceptance rate than citizens of HICs, such as United States (SolisArce et al., 2021). Prioritising the vaccination of poor countries instead of booster doses for wealthy ones at this moment would be in the best interest for all parties involved from either a nationalistic or cosmopolitan perspective since it will diminish the threat of potential novel emerging variants in poor countries which would spread worldwide and inevitably affect everyone (UN, 2021).

Through a more consequentialist scope, someone could claim that if global herd immunity, as a collective good, is the primary goal and desirable outcome, prioritising the vaccination of poor country populations instead of administering booster-jabs to citizens of wealthy nations, who already have a sufficient coverage, would be the right decision in order achieve it and maximise benefits. If wealthy populations get the booster, it might protect them from the danger of harm from viral infection in the short-term, but in the long term they will worsen the devastating consequences of unfair COVID-19 vaccine allocation and distribution. Most likely new variants of the virus will emerge in countries where the majority of the population would still remain unvaccinated, which will inevitably spread universally and cause the existing vaccinations to once again become insufficient and hence the need for more boosters will emerge in a never-ending vicious cycle. I can conclude that, this action's negative social consequences will prevail over the positive ones and therefore I consider it ethically unsuitable.

Another possible way to examine the issue is through the principle of the least restrictive scenario, which represents a utilitarian principle and is a key principle in public health ethics, but first we need to define its proper formulation (Childress et al., 2002). For the purpose of this paper, I will utilise this principle to determine the adoption of the right vaccination policy to achieve the goal of global herd immunity, taking into account the criterion of the least violation of personal rights as well (Gostin, 2008). However, an interpretation of what might be leaning towards restrictiveness can possibly emphasise more the potential harm arising from 
particular policies, rather than intrusion of rights and freedoms (Pugh \& Douglas, 2016). Hence, if a policy poses more risks for people, it can be considered more restrictive compared to the alternative ones irrespective of whether it infringes on freedoms or not. Applying this rationale on the booster issue, I tend to believe that the least restrictive alternative would be the alternative that carries the lowest threat of harm for the global population, in agreement with the desirable goal of herd immunity. Therefore, the implementation of the booster-shot policy for wealthy countries' populations rather than the distribution of these vaccines to poor countries where the majority of people remain unvaccinated, would be highly controversial since it will most likely prolong the COVID-19 pandemic, act against the universal goal of herd immunity and cause more harm in a global scale through the subsequent consequences of this action, such as potential new serious variants of the virus or further lockdowns and in-house isolation globally that could be seen as a violation of human freedom and autonomy. ${ }^{10}$

\section{Conclusion}

The COVID-19 pandemic brought again into light the issue of even, equitable allocation and distribution of scarce resources, such as the novel COVID-19 vaccine. It still remains controversial whether a country should distribute doses to its own citizens or if distribution should occur at a global scale and which principles or values should govern each scenario. I support global vaccine distribution with higher priority given to populations of poor and developing countries in an attempt to help the worst-off individuals with the most urgent needs. Globally, older individuals and front-line healthcare professionals (under certain criteria) should be prioritised along with people with a higher risk of severe infection and subsequent death. Ethical values such as benefiting the neediest people, decreasing social gaps, saving as many lives as possible and keeping society operating ought to be reflected in our prioritisation for even allocation and distribution. Equitable global vaccine allocation can be accomplished even at this point if wealthy countries, which now have a good level of coverage against the virus, allow the redistribution of surplus doses to those who have been deprived of them, through the COVAX initiative which can guarantee fairness and equity for every country in the world.

\section{References}

ACHESON, R. M. (1978): The definition and identification of need for healthcare. In: Journal of Epidemiology and Community Health, 32(1), pp. 10-15.

ADLER M. (2012): Well-being and fair distribution: Beyond cost-benefit analysis. Oxford: Oxford University Press.

ALEMAYEHU, C., MITCHELL, G. \& NIKLES, J. (2018): Barriers for conducting clinical trials in developing countries- a systematic review. In: International Journal for Equity in Health, 17(1), p. 37.

AMORE, S., PUPPO, E., MELARA, J., TERACCIANO, E., GENTILI, S. \& LIOTTA, G. (2021): Impact of COVID-19 on older adults and role of long-term care facilities during early stages of epidemic in Italy. In: Scientific Reports, 11(1), pp. 1-13.

ARORA, C., SAVULESCU, J., MASLEN, H., SELGELID, M. \& WILKINSON, D. (2016): The intensive care lifeboat: A survey of lay attitudes to rationing dilemmas in neonatal intensive care. In: BMC Medical Ethics, 17(1), pp. 1-9.

ASCHWANDEN, C. (2021): Five reasons why COVID herd immunity is probably impossible. In: Nature, 591(7851), pp. 520-522.

BAYER, R., BERNHEIM, R. G., CRAWLEY, L., M., DANIELS, N., GOODMAN, K., KASS, N., LO, B. et al. (2011): Ethical considerations for decision making regarding allocation of

\footnotetext{
${ }^{10}$ However, utilitarianism liberties and rights are important as far as they protect welfare, which is all that matters.
} 
mechanical ventilators during a severe influenza pandemic or other public health emergency. In: Centers for Disease Control and Prevention, July 1. [online] [Retrieved August 11, 2021] Available at: https://www.cdc.gov/about/advisory/pdf/VentDocument_Release.pdf.

BECKER, L. C. (1990): Reciprocity. Chicago: University of Chicago Press.

BEECHER, H. K. \& DORR, H. I. (1970): Research and the individual: Human studies. Boston: Little, Brown and Company.

BOGNAR, G. (2008): Age-weighting. In: Economics and Philosophy, 24(2), pp. 167-189.

BONG, C. L., BRASHER, C., CHIKUMBA, E., MCDOUGALL, R., MELLIN-OLSEN, J. \& ENRIGHT, A. (2020): The COVID-19 pandemic: Effects on low- and middle-income countries. In: Anesthesia \& Anelgesia, 131(1), pp. 86-92.

BROWN, C. S., MEPHAM, S. \& SHORTEN, R. J. (2017): Ebola virus disease: An update on epidemiology, symptoms, laboratory findings, diagnostic issues, and infection prevention and control issues for laboratory professionals. In: Clinics in Laboratory Medicine, 37(2), pp. 269284.

CALLAWAY, E. (2021): COVID vaccine boosters: The most important questions. In: Nature, 596(7871), pp. 178-180.

CHAKRABORTY, S., MALlAJOSYULA, V., TATO, C. M., TAN, G. S. \& WANG, T. T. (2021): SARS-CoV-2 vaccines in advanced clinical trials: Where do we stand? In: Advanced Drug Delivery Reviews, 172, pp. 314-338.

CHILDRESS, J. F., FADEN, R. R., GAARE, R. D., GOSTIN, L. O., KAHN, J., BONNIE, R. J., KASS, N. E. et al. (2002): Public health ethics: Mapping the terrain. In: The Journal of Law, Medicine \& Ethics, 30(2), pp. 170-178.

CHILDRESS, J. F. (2003): Triage in response to a bioterrorist attack. In: J. D. Moreno (ed.): In the wake of terror: Medicine and morality in a time of crisis. Cambridge, MA: MIT Press, pp. 77-93.

COHEN, J. \& KUPFERSCHMIDT, K. (2021): Rich countries cornered COVID-19 vaccine doses: Four strategies to right a 'scandalous inequity'. In: Science, 372(6544). May 26. [online] [Retrieved August 11, 2021] Available at: https://www.science.org/content/article/richcountries-cornered-covid-19-vaccine-doses-four-strategies-right-scandalous.

CRUESS, S. R. \& CRUESS, R. L. (2010): Medicine's social contract with society: Its nature, evolution, and present state. In: D. Bhugra, A. Malik \& G. Ikkos (eds.): Psychiatry's contract with society: Concepts, controversies, and consequences. New York: Oxford University Press. CULYER, A. J. (2012): Commodities, characteristics of commodities, characteristics of people, utilities, and the quality of life. In: R. Cookson \& K. Claxton (eds.): The humble economist: Tony Culyer on health, health care and social decision making. York: University of York, pp. 9-27.

D'SOUZA, D. \& DOWDY, D. (2021): Rethinking herd immunity and the COVID-19 response end game. In: Johns Hopkins Bloomberg School of Public Health, September 13. [online] [Retrieved in September 19, 2021] Available at: https://publichealth.jhu.edu/2021/what-isherd-immunity-and-how-can-we-achieve-it-with-covid-19.

DONG, M., HE, F. \& DENG, Y. (2021): How to understand herd immunity in the context of COVID-19. In: Viral Immunology, 34(3), pp. 174-181.

DWORKIN, R. (1981): What is equality? Part 2: Equality of resources. In: Philosophy and Public Affairs, 10(4), pp. 283-345.

EKStrom, A. M., BERGgren, C., TOMSON, G., GOSTIN, L. O., FriBERG, P. \& OTTERSEN, O. P. (2021): The battle for COVID-19 vaccines highlights the need for a new global governance mechanism. In: Nature Medicine, 27(5), pp. 739-740.

EMANUEL, E. J., PERSAD, G., UPSHUR, R., THOME, B., PARKER, M., GLICKMAN, A., ZHANG, C. et al. (2020): Fair allocation of scarce medical resources in the time of COVID19. In: The New England Journal of Medicine, 382(21), pp. 2049-2055. 
FIDLER, D. P. (2008): Influenza virus samples, international law, and global health diplomacy. In: Emerging Infectious Diseases, 14(1), pp. 88-94.

FINE, P., EAMES, K. \& HEYMANN, D. L. (2011): "Herd immunity": A rough guide. In: Clinical Infectious Diseases, 52(7), pp. 911-916.

FOOD \& DRUG ADMINISTRATION (2021): FDA approves first COVID-19 vaccine. In: Food \& Drug Administration, August, 23. [online] [Retrieved August 25, 2021] Available at: https://www.fda.gov/news-events/press-announcements/fda-approves-first-covid-19-vaccine. FORNI, G. \& MANTOVANI, A. (2021): COVID-19 vaccines: Where we stand and challenges ahead. In: Cell Death \& Differentiation, 28(2), pp. 626-639.

GATES, B. \& GATES, M. F. (2020): 2020 goalkeepers report, COVID-19 a global perspective. In: Bill \& Melinda Gates Foundation, September. [online] [Retrieved July 27, 2021] Available at: https://www.gatesfoundation.org/goalkeepers/report/2020-report/\#GlobalPerspective

GIUBILINI, A. (2019): An argument for compulsory vaccination: The taxation analogy. In: Journal of Applied Philosophy, 37(3), pp. 446-466.

GIUBILINI, A. (2021): Vaccination ethics. In: British Medical Bulletin, 137(1), pp. 4-12.

GOLDSTEIN, J. R., CASSIDY, T. \& WACHTER, K. W. (2021): Vaccinating the oldest against COVID-19 saves both the most lives and most years of life. In PNAS, 118(11), p. e2026322118.

GOSTIN, L. (2008): Public health law: Power, duty, restraint, revised and expanded $2^{\text {nd }}$ ed. Berkeley \& Los Angeles: California University Press.

GRIFFIN, J. (1988): Well-being: Its meaning, measurement and moral importance. Oxford: Clarendon Press.

HELD, D. \& MAFFETTONE, P. (2017): Moral cosmopolitanism and democratic values. In: Special Issue: Democracy Beyond Borders, 8(56), pp. 54-64.

HOLTUG, N. (2010): Persons, interests, and justice. Oxford: Oxford University Press.

INTERNATIONAL MONETARY FUND (2020): A crisis like no other, an uncertain recovery. In: International Monetary Fund World Economic Outlook, June. [online] [Retrieved July 11, 2021] Available at: https://www.imf.org/en/Publications/WEO/Issues/2020/06/24/WEOU pdateJune2020

KANG, S. J. \& JUNG, S. I. (2020): Age-related morbidity and mortality among patients with COVID-19. In: Infection and Chemotherapy, 52(2), pp. 154-164.

KERSTEIN, S. J. (2017): Dignity, disability, and lifespan. In: Journal of Applied Philosophy, 34(5), pp. 635-650.

KLASS, P. \& RATNER, A. J. (2021): Vaccinating children against COVID-19- the lessons of measles. In: The New England Journal of Medicine, 384(7), pp. 589-591.

LEE, K., WORNSOP, C. Z., GREPIN, K. A. \& KAMRADT-SCOTT, A. (2020): Global coordination on cross-border travel and trade measures crucial to COVID-19 response. In: Lancet, 395(10237), pp. 1593-1595.

LIM, W. \& ZHANG, P. (2020): Herd immunity and a vaccination game: An experimental study. In: Plos One, 15(5), p. e02232652.

LOEMBE, M. M. \& NKEGASONG, J. N. (2021): COVID-19 vaccine access in Africa: Global distribution, vaccine platforms, and challenges ahead. In: Immunity, 54(7), pp. 1353-1362.

MALLAPATY, S. (2020): The coronavirus is most deadly if you are older and male - new data reveal the risks. In: Nature, 585(7823), pp. 16-17.

MARTINI, M., GAZZANIGA, V., BRAGAZZI, N. L. \& BARBERIS, I. (2019): The Spanish influenza pandemic: A lesson from history 100 years after 1918. In: Journal of Preventive Medicine and Hygiene, 60(1), pp. e64-e67.

MATHIEU, E., RITCHIE, H., ORTIZ-OSPINA, E., ROSER, M., HASELL, J., APPEL, C., GIATTINO, C. et al. (2021): A global database of COVID-19 vaccinations. In: Nature Human Behaviour, 5(7), pp. 947-953. 
MAVES, R. C., DOWNAR, J., DICHTER, J., SPRUNG, C. L. \& CHRISTIAN, M. D. (2020): Triage of scarce critical care resources in COVID-19: An implementation guide for regional allocation. In: Chest, 158(1), pp. 212-225.

MAXMEN, A. (2021): COVID boosters for wealthy nations spark outrage. In: Nature, EPub ahead of print.

MCNEAL, K. A., GOLDIN, S., NANNEI, C., SPARROW, E. \& TORELLI, G. (2016): The 2015 global production capacity of seasonal and pandemic influenza vaccine. In: Vaccine, 34(45), pp. 5410-5413.

MCNEIL, Jr, D. (2020): How much herd immunity is enough? In: The New York Times, April 2. [online] [Retrieved July 12, 2021] Available at: https://www.nytimes.com/2020/12/ 24/health/herd-immunity-covid-coronavirus.html.

MILLER, J., SHIELDS, M. \& FARGE, E. (2021): U.S. joins WHO programme aimed at boosting COVID-19 fight. In: Reuters, February 9. [online] [Retrieved July 16, 2021] Available at: https://www.reuters.com/article/us-health-coronavirus-who-act-us-idUSKBN2A91N2

NELSON, S. H. (2002): The West's moral obligation to assist developing nations in the fight against HIV/AIDS. In: Health Care Analysis, 10(1), pp 87-108.

NIELSEN, L. (2021): Pandemic prioritarianism. In: Journal of Medical Ethics, (Online First), pp. 1-4.

PADMA, T. V. (2021): COVID vaccines to reach poorest countries in 2023-despite recent pledges. In: Nature, 595(7867), pp. 342-343.

PARFIT, D. (1984): Reasons and persons. Oxford: Oxford University Press.

PARFIT D. (1997): Equality and priority. In: Ratio, 10(3), pp. 202-221.

PAVEL, C. E. (2009): Cosmopolitanism, nationalism and moral opportunity costs. In: Polity, 41(4), pp. 489-513.

PEIFFER-SMADJA, N., ROZENCWAJG, S., KHERABI, Y., YAZDANPANAH, Y. \& MONTRAVERS, P. (2021): COVID-19 vaccines: A race against time. In: Anaesthesia Critical Care \& Pain Medicine, 40(2), p. 100848.

PERSAD, G., WERTHEIMER, A. \& EMANUEL, E. J. (2009): Principles for allocation of scarce medical interventions. In: Lancet, 373(9661), pp. 423-431.

POGGE, T. W. (1992): Cosmopolitanism and sovereignty. In: Ethics, 103(1), pp. 48-75.

PUGH, J. \& DOUGLAS, T. (2016): Justifications for non-consensual medical intervention: From infectious disease control to criminal rehabilitation. In: Criminal Justice Ethics, 35(3), pp. 205-229.

RAUHALA, E. \& ABUTALEB, Y. (2020): U.S. says it won't join WHO-linked effort to develop, distribute coronavirus vaccine. In: Washington Post, September, 1. [online] [Retrieved in July 30, 2021] Available at: https://www.washingtonpost.com/world/coronavirus-vaccinetrump/2020/09/01/b44b42be-e965-11 ea-bf44-0d31c85838a5_story.html

RAWLS, J. (1971): A theory of justice. Cambridge, MA: Harvard University Press.

SADMI, E., CHEN, Y., DOURADO, I., FARAN-PERACH, I., FURLER, J., HANGOMA, P., PIYA, H. et al. (2020): Health equity and COVID-19: Global perspectives. In: International Journal for Equity in Health, 19(1), pp. 1-16.

SAMUELSON, P. A. (1954): The pure theory of public expenditure. In: The Review of Economics and Statistics, 36(4), pp. 387-389.

SAVULESCU, J. \& WILKINSON, D. (2020): Who gets the ventilator in the coronavirus pandemic? These are the ethical approaches to allocating medical care. In: $A B C$ News Online, March 17. [online] [Retrieved September 17, 2021] Available at: https://www.abc.net.au/news/ 2020-03-18/ethics-of-medical-care-ventilator-in-the-coronavirus-pandemic/12063536

SCANLON T. (1998): What we owe to each other. Cambridge, MA: Harvard University Press. SCHEFFLER, S. (2002): Boundaries and allegiances: Problems of justice and responsibility in liberal thought. Oxford: Oxford University Press. 
SHIELDS, L. (2020): Sufficientarianism. In: Philosophy Compass, 15(11), pp. 1-10.

SOLIS-ARCE, J. S., WARREN, S. S., MERIGGI, N. F., SCACCO, A., MCCURRY, N., VOORS, M., SYUNYAEV, G. et al. (2021): COVID-19 vaccine acceptance and hesitancy in low- and middle-income countries. In: Nature Medicine, 27(8), pp. 1385-1394.

TAN, K. C. (2004): Justice without borders: Cosmopolitanism, nationalism, and patriotism (Contemporary political theory). Cambridge, UK: Cambridge University Press.

THE LANCET INFECTIOUS DISEASES. (2021): COVID-19 vaccine equity and booster doses. In: Lancet Infectious Diseases, 21(9), p. 1193.

TORRES, I., LOPEZ-CEVAllos, D., ARTAZA, O., PROFETA, B., KANG, J. \& MACHADO, C. V. (2021): Vaccine scarcity in LMICs is a failure of global solidarity and multilateral instruments. In: Correspondence, 397(10287), p. 1084.

TSUCHIYA, A. (2000): QALYs and ageism: Philosophical theories and age weighting. In: Health Economics, 9(1), pp. 57-68.

UNESCO (2021): UNESCO calls for COVID-19 vaccines to be considered a global public good. In: UNESCO, February, 24. [online] [Retrieved July 20, 2021] Available at https://en.unesco.org/news/unesco-calls-covid-19-vaccines-be-considered-global-public-good UNITED NATIONS (2021): COVID variants 'winning the race against vaccines' warns WHO chief. In: $U N$ News, July 7. [online] [Retrieved August 20, 2021] Available at: https://news.un.org/en/story/2021/07/1095432

UNITED NATIONS (2021): COVID-19 vaccines must be global public good, secretarygeneral says, announcing 'only together' campaign to encourage sharing of technology, doses. In: United Nations, March 11. [online] [Retrieved July 20, 2021] Available at: https://www.un.org/press/en/2021/sgsm20620.doc.htm

UNIVERSITY COLLEGE LONDON (2021): Vaccine antibody levels start to wane at around 2-3 months. In: University College London, July 22. [online] [Retrieved August 18, 2021] Available at: https://www.ucl.ac.uk/news/2021/jul/vaccine-antibody-levels-start-wanearound-2-3-months

WAXMAN, M. J., MOSCHELlA, P., DUBER, H. C., MARTIN, D. R., BENZONI, T., ROTHMAN, R. E. \& SCHECHTER-PERKINS, E. M. (2021): Emergency department- based COVID-19 vaccination: Where do we stand? In: Academic Emergency Medicine, 28(6), pp. 707-709.

WINSOR, S., BENSIMON, C. M., SIBBALD, R., ANSTEY, K., CHIDWICK, P., COUGHLIN, K., COX, P. et al. (2014): Identifying prioritization criteria to supplement critical care triage protocols for the allocation of ventilators during a pandemic influenza. In: Healthcare Quarterly, 17(2), pp. 44-51.

WORLD HEALTH ORGANIZATION (2020): Commitment and call to action: Global collaboration to accelerate new COVID-19 health technologies. In: World Health Organization, April 24. [online] [Retrieved July 15, 2021] Available at: https://www.who.int/news/item/2404-2020-commitment-and-call-to-action-global-collaboration-to-accelerate-new-covid-19health-technologies.

WORLD HEALTH ORGANIZATION (2020): Protecting older people against COVID-19. In: World Health Organization, September 3. [online] [Retrieved August 11, 2021] Available at: https://www.who.int/westernpacific/news/feature-stories/detail/protecting-older-people-agains t-covid-19

WORLD HEALTH ORGANIZATION (2020): Seventy-third World Health Assembly: COVID-19 response. In: World Health Organization, May 18. [online] [Retrieved July 22, 2021]. Available at: https://apps.who.int/gb/ebwha/pdf_files/WHA73/A73_CONF1Rev1en.pdf

WORLD HEALTH ORGANIZATION (2021): Interim statement on COVID-19 vaccine booster doses. In: World Health Organization, August 10. [online] [Retrieved August 18, 2021] 
Available at: https://www.who.int/news/item/10-08-2021-interim-statement-on-covid-19vaccine-booster-doses

WORLD HEALTH ORGANIZATION (2021): Statement on the eighth meeting of the international health regulations (2005) emergency committee regarding the coronavirus disease (COVID-19) pandemic. In: World Health Organization, July 15. [online] [Retrieved July 28, 2021] Available at: https://www.who.int/news/item/15-07-2021-statement-on-the-eighthmeeting-of-the-international-health-regulations-(2005)-emergency-committee-regarding-thecoronavirus-disease-(covid-19)-pandemic

WORLD HEALTH ORGANIZATION (2021): Vaccine inequity undermining global economic recovery. In: World Health Organization, July 22. [online] [Retrieved August 8, 2021] Available at: https://www.who.int/news/item/22-07-2021-vaccine-inequity-underminingglobal-economic-recovery

WORLD HEALTH ORGANIZATION (2021): WHO director-general's opening remarks at the media briefing on COVID-19- 4 August 2021. In: World Health Organization, August 4. [online] [Retrieved August 18, 2021] Available at https://www.who.int/directorgeneral/speeches/detail/who-director-general-s-opening-remarks-at-the-media-briefing-oncovid-4-august-2021

WRIGHT, J. (1998). Development and importance of health needs assessment. In: $B M J$, 316(7140), pp. 1310-1313.

YAMEY, G. (2021): Rich countries should tithe their vaccines. In: Nature, 590(7847), p. 529. YIGIT, M., OZKAYA-PARLAKAY, A. \& SENEL, E. (2021). Evaluation of COVID-19 vaccine refusal in parents. In: The Pediatric Infectious Disease Journal, 40(4), pp. e134-e136. YUNUS, M., DONALDSON, C. \& PERRON, J. L. (2020): COVID-19 vaccines a global common good. In: Healthy Longevity, 1(1), pp. e6-e8.

ZERHOUNI, E. (2019): GAVI, the vaccine alliance. In: Cell, 179(1), pp. 13-17.

ZUCKER, H. A., ADLER, K. P., BERENS, D. P., BLEICH, R. J. D., BRYNNER, R., BUTLER, K. A., CALDERON, Y. et al., (2015): Ventilator allocation guidelines. In: New York State Department of Health, November. [online] [Retrieved August 11, 2021] Available at: https://www.health.ny.gov/regulations/task_force/reports_publications/docs/ventilator_guideli nes.pdf 